\title{
Article \\ Resistance to Leaf and Yellow Rust in a Collection of Spanish Bread Wheat Landraces and Association with Ecogeographical Variables
}

\author{
Fernando Martínez-Moreno ${ }^{1, *}$, Patricia Giraldo ${ }^{2} \mathbb{D}$, Cristina Nieto $^{3}\left(\mathbb{D}\right.$ and Magdalena Ruiz $^{3}$ (D) \\ 1 Agronomy Department, School of Agricultural Engineering, University of Seville, 41013 Seville, Spain \\ 2 Biotechnology-Plant Biology Department, School of Agricultural, Food and Biosystems Engineering, \\ Universidad Politécnica de Madrid, 28040 Madrid, Spain; patricia.giraldo@upm.es \\ 3 National Plant Genetic Resources Centre (CRF), National Institute for Agricultural and Food Research and \\ Technology, CSIC, 28800 Alcalá de Henares, Spain; cristina.nieto@inia.es (C.N.); mruiz@inia.es (M.R.) \\ * Correspondence: fernan@us.es
}

check for updates

Citation: Martínez-Moreno, F.; Giraldo, P.; Nieto, C.; Ruiz, M. Resistance to Leaf and Yellow Rust in a Collection of Spanish Bread Wheat Landraces and Association with Ecogeographical Variables. Agronomy 2022, 12, 187. https://doi.org/ 10.3390/agronomy12010187 Academic Editor: Rohit Mago Received: 8 December 2021 Accepted: 10 January 2022 Published: 13 January 2022

Publisher's Note: MDPI stays neutral with regard to jurisdictional claims in published maps and institutional affiliations.

Copyright: (C) 2022 by the authors. Licensee MDPI, Basel, Switzerland. This article is an open access article distributed under the terms and conditions of the Creative Commons Attribution (CC BY) license (https:// creativecommons.org/licenses/by/ $4.0 /$ )

\begin{abstract}
A collection of 84 bread wheat Spanish landraces were inoculated with three isolates of leaf rust and one of yellow rust at the seedling stage in controlled conditions. The latency period of leaf rust on the susceptible landraces was also assessed. An extended collection of 149 landraces was planted in three locations in field trials to evaluate the naturally occurring leaf and yellow rust severity. Several landraces (36) were resistant to one leaf rust isolate at the seedling stage, but only one was resistant to all three isolates. Landraces resistant to PG14 leaf rust isolate originated from areas with higher precipitation and more uniform temperatures. Many resistant landraces were from the north-west zone of Spain, a region with high precipitation and uniform temperatures. Results from the field trials also confirmed this trend. Landraces from the north-west also possessed a longer latency period of leaf rust, an important component of partial resistance. Regarding yellow rust, 16 landraces showed a lower disease severity in the seedling tests. Again, the resistant landraces mostly originated from areas with higher precipitation (especially in winter) and more uniform temperature.
\end{abstract}

Keywords: Puccinia triticina; Puccinia striiformis; Triticum aestivum; latency period; genetic resources; ecogeographical variation

\section{Introduction}

Wheat landraces in Spain have been acknowledged for their diversity in different studies [1,2]. Regarding common or bread wheat (Triticum aestivum L. subsp. aestivum), winter or facultative landraces occupied a pivotal position and a great acreage in the central Spanish plateau. Candeal, Chamorro, Jeja (or Xexa or Xeixa), Negrillo, or Rojo landraces were popular among Castilian and Aragonese farmers that selected the best genotypes for adaptation, yield, and bread-making quality. Furthermore, Spain is a country with a long tradition of bread consumption, with a mean lifelong consumption of $0.75 \mathrm{~kg} /$ person per day in the 19th century [3]. The Spanish collection of wheat landraces, conserved at the National Plant Genetic Resources Centre (CRF), has been assessed in past $[4,5]$ and recent studies $[2,6,7]$.

Leaf rust, caused by the fungus Puccinia triticina Eriks., is an important wheat disease worldwide and in Spain. Recently, it was reported as the main biotic constraint to world wheat production (ahead of fusarium head blight, septoria tritici blotch, and yellow rust), reducing the potential global production by 4.3\% (world grain production in 2017 was 772 Mt; FAO, 2021) [8]. Yellow rust, caused by the fungus P. striiformis, is another wheat rust disease accounting for a $20 \mathrm{Mt}$ grain loss worldwide (2.7\%). From 2012, this rust produced outbreaks in Europe, including Spain, where the Warrior race was virulent on most bread wheat cultivars [9]. 
In Spain, both rust diseases, together with Septoria tritici blotch, are the main wheat diseases, and farmers must apply fungicides and/or buy seeds of resistant cultivars for their control. Resistance is the most sustainable method to control plant diseases. Leaf and yellow rust resistance are frequently deployed in the wheat cultivars, but the rust pathogen is able to develop new virulent races rendering these cultivars susceptible [10,11]. Plant breeders react by introducing new $R$ (resistance) genes in their wheat material which gives a hypersensitive response (HR) and act in a gene-for-gene manner with the pathogen [12]. $R$ genes giving resistance to leaf rust are called $L r$ and are the ones giving resistance to yellow rust $Y r$. The molecular basis of this resistance is an interaction between certain factors of the pathogen called effectors with some receptors of the plant that are the product of the resistance gene [13]. Some of these genes come from wild relatives such as Lr39 from T. tauschii [14] or Yr15 from T. turgidum subsp. diccocoides [15]. Bread wheat landraces are also a source of leaf rust resistance such as Malakof ( $L r 1)$, Alfredo Chaves (Lr3) o Hussar (Lr11), or the famous 'miserable' landrace PI 178383 that Jack Harlan found in Shemdinli (Turkey), possessing Yr10 and three more minor genes of resistance to yellow rust [16,17]. Partial resistance (PR) is a type of resistance that results in a slower epidemic build-up of the disease and acts in the absence of hypersensitivity. PR has distinctive features compared to HR: it is polygenic, horizontal (or race non-specific), incomplete (although its effect is larger in adult plants) and is considered of durable nature. PR to leaf rust has been found in common wheat landraces, such as the Japanese landrace Akabozu [18]. Despite its polygenic nature, PR can also be controlled by single genes, such as Lr34, which was firstly described in the Brazilian cultivar Frontana, which in turn originated from the Italian 'Mentana'. This gene could be traced back to one of the parents of 'Mentana': the Japanese landrace Akagomughi or the Italian landrace Rieti [19].

The objective of this study was to evaluate the resistance to leaf rust and yellow rust in a germplasm collection of Spanish common wheat and to relate it with local ecological variables in geographical areas from which the landraces originated.

\section{Materials and Methods}

\subsection{Plant Material}

The 84 landraces used in the analysis of rust resistance at the seedling stage in a greenhouse are a representative subset of the Spanish collection of common wheat, composed of 522 landraces [20]. This subset is formed by single-seed-descent (SSD) lines derived from the original landraces (identified by their bank number). Another set of 149 Spanish landraces from different regions (field set) was evaluated at the adult plant stage in field experiments.

\subsection{Fungal Material}

Three single pustule isolates of Puccinia triticina were used for the hypersensitive resistance study: Jerez Califa 13 (JC13), Huesca 14 (HU14), and Peralta García 14 (PG14) collected respectively from Jerez de la Frontera (Cádiz) in the south of the country, and from Huesca and Peralta (Navarra), in the north of the country. Inoculation on a Thatcher/Lr isolines differential set showed that the isolates were virulence/avirulence on the following Lr genes:

- $\quad$ JC13: Lr1, Lr2c, Lr3, Lr3bg, Lr10, Lr14a, Lr14b, Lr17, Lr20, LrB/Lr2a, Lr3ka, Lr9, Lr11, Lr16, Lr18, Lr24, Lr26, Lr30.

- $\quad$ HU14: Lr1, Lr3, Lr3bg, Lr3ka, Lr11, Lr14a, Lr14b, Lr17, Lr26, Lr30, LrB/Lr2a, Lr2c, Lr9, Lr10, Lr16, Lr18, Lr20, Lr24, Lr28.

- $\quad$ PG14: Lr1, Lr3, Lr3bg, Lr10, Lr14a, Lr14b, Lr16, Lr17, Lr18, Lr20, Lr26, Lr30, LrB/Lr2a, Lr2c, Lr3ka, Lr9, Lr11, Lr18, Lr24, Lr28.

For the PR experiments (see Section 2.4) regarding leaf rust, only the isolate JC13 was used. For yellow rust, isolate Ecija Jerezano 18 (EJ18), collected from Ecija (South Spain), was employed. Its virulence/avirulence spectrum was the following: $Y_{r} 1, Y_{r} 6, Y_{r} 7, Y_{r}$, Yr17, Yr18, Yr32/Yr2, Yr3, Yr4, Yr5, Yr8, Yr10, Yr15, Yr24, Yr26, Yr27. 


\subsection{Experiment of Hypersensitive Resistance to Leaf Rust and Yellow Rust at Seedling Stage in the Greenhouse}

For leaf rust experiments, landraces of the representative subset were sown in plastic trays of $60 \times 40 \mathrm{~cm}$ in soil made of peat moss and sand (1:1 vol./vol.). In each tray, 4 plants of 16 landraces plus the susceptible checks (Thatcher and Califa) were grown in a greenhouse at the Technical School of Agronomic Engineering (ETSIA, University of Seville). Inoculations were performed in two different experiments at two different plant seedling stages, first and fifth leaf (12 and 16 Zadoks scale) [21]. Plants were inoculated by dusting $4 \mathrm{mg}$ of uredospores per tray mixed with talc powder (1:40 vol./vol.), which resulted in deposition of approximately 70 spores $/ \mathrm{cm}^{2}$. Uredospores were stored in an ultra-freezer at $-80^{\circ} \mathrm{C}$. They were taken out and given a heat treatment in a $40{ }^{\circ} \mathrm{C}$ water bath for $5 \mathrm{~min}$ to break the cold-induced dormancy of the spores. Leaves were laid with the adaxial side up and fixed on the soil with metallic hairpins to obtain a more uniform inoculation. Inoculated plants were placed in an incubation compartment within the greenhouse at $18-20^{\circ} \mathrm{C}$, with darkness and humidity at saturation (by means of ultrasonic humidifiers) for $15 \mathrm{~h}$. The next day, hairpins were removed from the leaves and plants were transferred back to their greenhouse compartment where the temperature ranged $15-25^{\circ} \mathrm{C}$. At 13 days after inoculation, when the number of pustules in the susceptible check no longer increased, infection type (IT) was assessed in each leaf of the landraces, using the McNeal scale [22]. In most cases, the IT score agreed in all four leaves of each landrace. This scale is 0-9, where an IT lower than 7 indicated a (hypersensitive) resistant or incompatible response in the landraces, while an IT of 7 or more indicated a susceptible or compatible response. Hypersensitive resistance is characterized by necrotic foliar tissue surrounding the pustule and macroscopically seen as yellowish leaf spots. Disease severity (DS) was assessed following the modified scale of Cobb [23], expressed as the proportion of foliar surface covered by pustules with respect to the total surface (from 0 to $100 \%$ ). Landraces with DS from 0 to $10 \%$ were considered resistant since hypersensitive resistance usually results in fewer and smaller pustules that greatly reduce the severity [24], and those with DS values higher than $10 \%$ were regarded as susceptible.

For yellow rust experiments, plants were grown in smaller trays that permitted fitting in a refrigerator, where inoculated plants were stored at $10{ }^{\circ} \mathrm{C}$ for $24 \mathrm{~h}$ in total darkness. Two susceptible checks were also sown in each tray (Little Club and Avocet). Disease parameters were evaluated in the same way as for leaf rust.

\subsection{Experiment of Partial Resistance to Leaf Rust at Seedling Stage in the Greenhouse}

For this experiment, the 78 landraces of the representative subset showing a high infection type (IT $\geq 7$ ) when inoculated with isolate JC13 were sown again in plastic trays, being the susceptible check, Little Club, and the partially resistant check, Akabozu. Four first leaves of each landrace were inoculated, this time using a settling tower to improve the uniformity of the inoculation. Pustules were counted daily from the first day that appeared with a pocket lens. The latency period (LP) was the time at which $50 \%$ of the total number of pustules appeared.

\subsection{Leaf and Yellow Rust Evaluation at the Adult Plant Stage in the Field Experiments}

A group of wheat landraces (field set) were tested for leaf rust at the adult plant stage in field plots in 1996-1997 at three southern locations: 149 landraces in Cordoba (37.89155 N, $4.77275 \mathrm{~W}), 74$ landraces in Jerez de la Frontera ( 36.68645 N, 6.13606 W), and 145 landraces in Granada (37.18817 N, 3.60667 W). In addition, 34 landraces were tested for yellow rust in Cordoba. The landraces were sown in $1 \mathrm{~m}$ furrows. Field infection was natural, and leaf rust severity was assessed following the modified Cobb scale [23], expressed as a proportion of foliar surface covered by pustules with respect to the total surface (from 0 to $100 \%$ ). Yellow rust severity was also taken according to the same scale. 


\subsection{Agronomic Characterization}

Seven qualitative (growth habit, awn length, awn color, spike density, glume hairiness, glume color, and seed color) and five quantitative agromorphological traits (days to heading and to maturity, plant height, spike length, and spikelets per spike) were obtained from a previous study [20]. Days to heading and plant height were also recorded for the field set from the rust resistance field experiment in the 1996-1997 season. All traits were evaluated according to the International Board of Plant Genetic Resources (IBPGR) from five different plants in each landrace.

\subsection{Ecogeographical Characterization}

Seventy-three landraces of the representative subset and 145 landraces of the field set were assigned to one of the nine agroecological zones for wheat defined on the basis of historical yield records and province of origin of the landrace [25]. Geographic coordinates (latitude, longitude, and altitude) of the collection site were obtained for 50 landraces and 144 landraces of the subset and the field set, respectively, from the passport data of each landrace [26]. The accuracy of the geographic coordinates was checked with Google Earth $\Subset$. Data on 75 ecogeographical variables classified into three components were gathered: bioclimatic variables (67), geophysical variables (3), and edaphic variables (5) (see Table S1). The bioclimatic variables (1950-2000 period) were related to temperature and rainfall, including some indexes which analyzed the relationships between both climatic effects. The geophysical variables were related to solar radiation (northness, eastness, and elevation), and the edaphic parameters were related to the physical and/or chemical conditions of the soil ( $\mathrm{pH}$, bulk density, and clay and sand content). The values of the ecogeographical variables were extracted for each collection site from raster layers with a 2.5 arc min resolution ( $5 \times 5 \mathrm{~km}$ cell grid) obtained from various sources compiled by CAPFITOGEN [27].

\subsection{Data Analyses}

For qualitative traits, significant differences between the frequencies in the rustresistant and susceptible groups were checked by chi-square test ( $p$-value $<0.05)$. For quantitative variables, a homogeneity test (Levene's test) for variances and a $t$-test for means ( $p$-value $<0.05$ ) were used to compare the resistant and susceptible groups. For those variables that deviated from equality of variances, the nonparametric Kruskal and Wallis test was used [28]. Relationships between variables were examined using the Pearson correlation coefficient $(p<0.05)$. In order to determine a threshold value of the ecogeographical variables to classify the genotypes in the resistant and susceptible groups, a regression tree was performed using the most significant with no correlated ecogeographical variables as regression variables. Statistical analyses were performed with the software programs $\mathrm{R}$ version 3.5.2 and Infostat version 6.12 software.

\section{Results}

\subsection{Leaf Rust (Hypersensitive) Resistance of the Representative Subset at Seedling Stage in} the Greenhouse

\subsubsection{Correlations between Disease Parameters}

A subset of 84 landraces representative of the Spanish landraces was evaluated for leaf rust resistance at the seedling stage in greenhouse tests (IT, DS, and LN) to the rust isolates JC13 and HU14 (first and fifth leaf stages), and PG14 (fifth leaf stage) (Table S2). Correlation analyses detected significant correlations between the first and fifth leaf scores for the three parameters (Figure 1). DS was positively and negatively correlated with IT and LN, respectively, in all the isolates. Between isolates, the correlation was significant $(p<0.05)$ only between IT values of HU14 and PG14. 


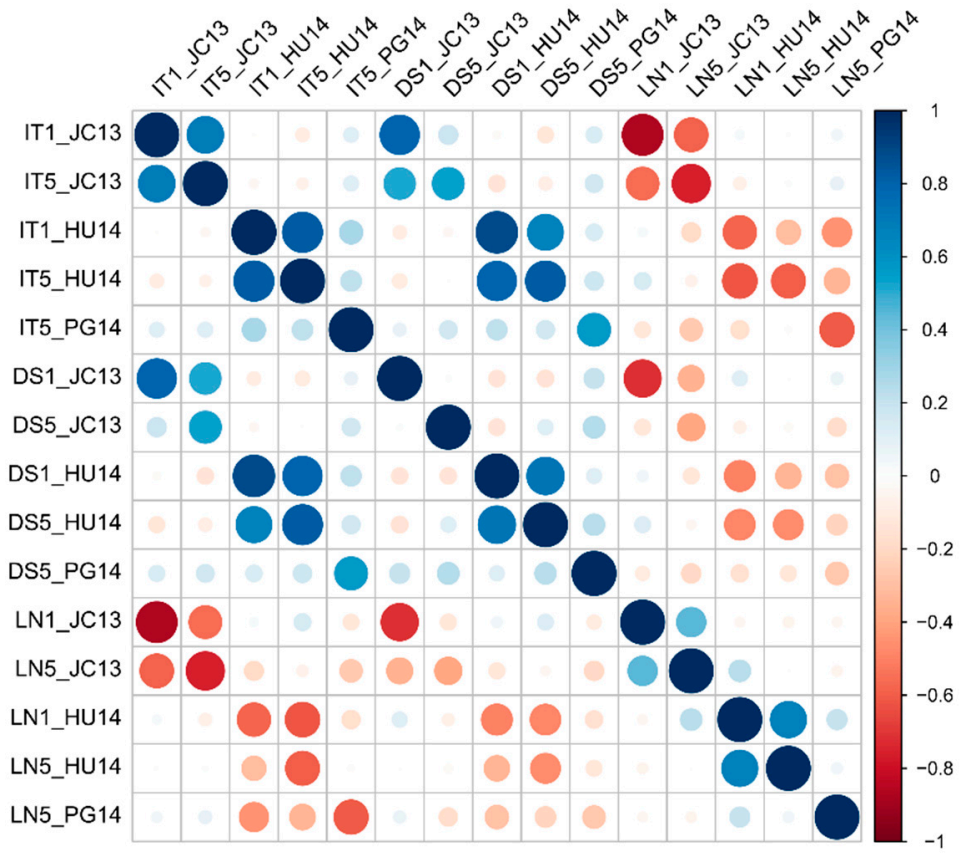

Figure 1. Pearson correlations between the disease parameters scored at the seedling stage: infection type (IT), disease severity (DS), and leaf necrosis (LN), for each leaf rust isolate: Jerez Califa 13 (JC13), Huesca 14 (HU14), and Peralta García 14 (PG14). The numbers 1 or 5 after the disease parameter indicate the first and fifth leaf, respectively. Coefficients $>|0.18|$ are significant $(p<0.05)$.

\subsubsection{Identification of Resistant Landraces to Leaf Rust}

Resistant landraces to each isolate were identified by their IT at the fifth leaf stage. First and fifth leaf scores were related therefore forward analyses were made with the fifth leaf response as it is better correlated with the adult plant response. Those landraces with IT values at the fifth leaf lower than 7 were considered resistant to the corresponding isolate. There were more susceptible than resistant landraces to the leaf rust isolates, mainly for PG14 (Table 1). In general, landraces were not resistant to more than one isolate. Only one landrace (BGE013157 from Jerez, Cádiz) presented simultaneous resistance against the three-leaf rust isolates. Three out of the four landraces resistant to PG14, were also resistant to HU14. The check variety Thatcher was susceptible to the three isolates, whereas Califa was resistant to HU14 and PG14 (Table S2). Landraces were also classified by their DS values as resistant (DS $\leq 10)$ and susceptible (DS > 10). According to this parameter, the frequency of susceptible landraces was lower than the frequency obtained according to the IT values but was also higher than the resistant landraces (Table 1). The classification of the check varieties as susceptible or resistant was similar to that obtained with the IT parameter, except for Thatcher, which was resistant to PG14 according to DS.

Table 1. Number of resistant landraces (IT $<7$ or DS $\leq 10$ ) to specific isolates of leaf rust at the seedling stage and at the adult stage in field experiments at three locations.

\begin{tabular}{cccccccccccccc}
\hline & \multicolumn{4}{c}{ Seedling Stage } & \multicolumn{3}{c}{ Adult Stage } \\
\hline Parameter/Isolate & \multicolumn{2}{c}{ JC13 $^{\mathbf{1}}$} & \multicolumn{2}{c}{ HU14 } & \multicolumn{2}{c}{ PG14 } & \multicolumn{2}{c}{ Cordoba } & \multicolumn{2}{c}{ Jerez } & Granada \\
\hline & No. & \% & No. & $\mathbf{\%}$ & No. & $\%$ & No. & $\%$ & No. & $\%$ & No. & $\%$ \\
\hline IT & 10 & 12 & 28 & 33 & 4 & 5 & - & - & - & - & - & - \\
DS & 34 & 40 & 37 & 44 & 39 & 46 & 10 & 6 & 10 & 13 & 5 & 4 \\
\hline
\end{tabular}

${ }^{1}$ Leaf rust isolates: JC13 = Jerez Califa 13, HU14 = Huesca 14, PG14 = Peralta García 14.

Resistant landraces, according to IT, had significant lower DS values than susceptible landraces for the three isolates (6.61 vs. 13.07 for JC13, 2.20 vs. 16.04 for HU14 and 4.15 vs. 
12.81 for PG14, $p<0.01)$. Table S2 shows that the most susceptible groups for IT generally showed higher DS values.

\subsubsection{Relations between Seedling Resistance to Leaf Rust and Agronomic Traits}

The only significant correlations detected between agronomic traits and IT values were for days to heading $(p<0.05)$ and days to maturity $(p<0.01)$ in JC13. Resistant landraces were generally earlier maturing than those recorded as susceptible, although the difference was not statistically significant (205 days to maturity vs. 207 days, $p=0.06$ ) (Figure 2a). For DS, a significant correlation was found with the number of spikelets per spike $(\mathrm{r}=0.26$, $p<0.05)$ in the HU14 isolate, having resistant landraces and a lower number of spikelets $(18$ vs. $19, p<0.05)$ (Figure $2 b)$.

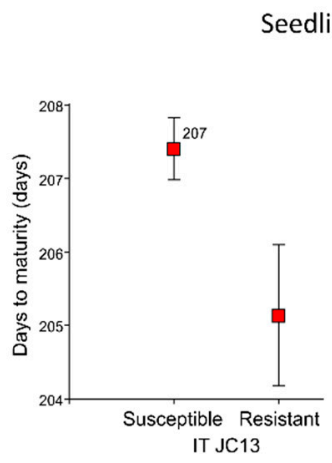

(a)

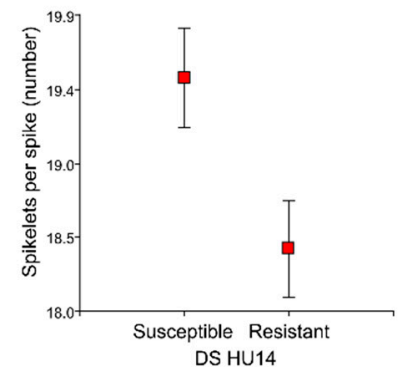

(b)

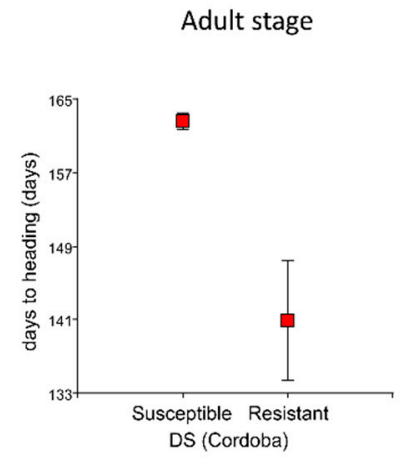

(c)

Figure 2. Differences in agronomic traits between leaf rust-resistant and susceptible landraces in (a) days to maturity for infection type (IT) to Jerez Califa 13 (JC13) at the seedling stage, (b) spikelet per spike for disease severity (DS) to Huesca 14 (HU14) at the seedling stage, and (c) days to heading for disease severity (DS) at adult stage in Cordoba locality.

3.1.4. Relations between Leaf Rust Seedling Resistance and Ecogeographical Variables of the Geographical Area of Origin

The association of evaluation data for leaf rust resistance with the environmental conditions of the collection sites of the assessed landraces could help to identify environments that are likely to impose selection pressure for the emergence of resistance genes. Most of the sites of the bread wheat landraces were assigned to one agroecological zone in Spain (Zones 1-9) [25]. Only those zones with more than five landraces were included in the analyses (Zones 1, 4 and 9). No significant differences for disease resistance based on IT values were found between zones for any isolates, whereas all the genotypes from Zone 1 (areas with high wheat yields in eastern and north-central Spain) were resistant to JC13 $(p<0.05)$ according to DS.

The relationships between 75 ecogeographical variables of the collection site and disease resistance according to IT and DS were studied (Table S1), except for PG14 and IT, since only three resistant landraces had geographic coordinates. Table 2 and Table S3 show the significant differences found between the resistant/susceptible groups for the ecogeographical variables. For the HU14 isolate, only the bulk density of soil was significantly different between the origin sites of the resistant and susceptible landraces, the resistant coming from zones with lower density. For JC13, no significant differences were found between resistant/susceptible groups, although landraces with lower DS values most likely came from areas with lower temperatures in the Driest quarter $\left(17.5^{\circ} \mathrm{C}\right.$ vs. $\left.20^{\circ} \mathrm{C}, p=0.06\right)$. Resistant landraces to PG14, according to DS, generally came from areas with higher precipitation, lower maximum temperatures in summer, and more uniform temperatures. 
Table 2. Ecogeographical variables ordered according to their significant differences $(p<0.05)$ between resistant (IT $<7$ or DS $\leq 10$ ) and susceptible landraces (IT $\geq 7$ or DS $>10$ ) to leaf rust at seedling.

\begin{tabular}{|c|c|c|c|c|}
\hline $\begin{array}{c}\text { Disease } \\
\text { Parameter }\end{array}$ & Isolate & $\begin{array}{c}\text { Bioclimatic } \\
\text { (Thermal Variables) }\end{array}$ & $\begin{array}{c}\text { Bioclimatic } \\
\text { (Hydric Variables) }\end{array}$ & Geophysical \\
\hline IT & HU14 & - & - & Density (-) \\
\hline DS & HU14 & - & - & Density $(-)$ \\
\hline DS & PG14 & $\begin{array}{c}\text { Temperature seasonality }(-)^{1} \\
\text { July maximum temperature }(-) \\
\text { Annual temperature range }(-) \\
\text { Maximum temperature of hottest month }(-) \\
\text { Mean daily temperature range }(-) \\
\text { August maximum temperature }(-)\end{array}$ & $\begin{array}{l}\text { Precipitation of wettest month }(+) \\
\text { Precipitation of wettest quarter }(+) \\
\text { March precipitation }(+) \\
\text { Annual precipitation }(+) \\
\text { October precipitation }(+) \\
\text { September precipitation }(+) \\
\text { December precipitation }(+) \\
\text { February precipitation }(+) \\
\text { Precipitation of coldest quarter }(+) \\
\text { April precipitation }(+) \\
\text { Precipitation of hottest quarter }(+) \\
\text { January precipitation }(+) \\
\text { August precipitation }(+)\end{array}$ & \\
\hline
\end{tabular}

${ }^{1}$ The $(+)$ or $(-)$ indicates the associations of high or low values of the variable with the resistant landraces (leaf rust isolates JC13 = Jerez Califa 13, HU14 = Huesca 14, PG14 = Peralta García 14).

\subsubsection{Leaf Rust Resistance at Adult Plant Stage in the Field Experiments}

Another group of landraces (field set), which included only 28 landraces of the representative set, were tested for leaf rust severity in field plots at three locations (Cordoba, Jerez, and Granada) in the south of Spain (Table S4). Significant correlations were detected between the DS evaluated in the three locations $(p<0.0001)$. The mean severity of the most susceptible genotypes was $80 \%$ in Cordoba and 70\% in Jerez and Granada. Seven landraces were resistant in more than one locality, and only one landrace (BGE011888) showed resistance in all three locations (Table S4).

Landraces with low DS at Cordoba location headed earlier (lower values of days to heading, 141 days vs. 163 days, $p<0.001$ ) (Figure 2c). Comparison of the disease resistance of landraces from Zone 9 (north-west zone of Spain) and 4 (Centre of Spain) revealed a higher frequency of resistant landraces from Zone 9 in the three locations $(p<0.05)$ (Figure 3). Zone 1 included less than five landraces, so it was excluded from the analyses.

Associations between ecogeographical variables and leaf rust resistance evaluated in the field experiments indicated that resistant landraces at Cordoba generally came from areas with higher precipitation, except in summer (Table S5). Resistant landraces at Jerez were from collecting sites with higher precipitation from September to April, more uniform temperatures (higher in the colder season and lower maximum values in summer) and lower soil clay content. Landraces recorded as resistant in Granada came from areas with more precipitation (mainly in summer), more uniform temperature, and were less hot in summer. An association between low soil $\mathrm{pH}$ and low DS values was detected at the three locations. All significant differences for the bioclimatic variables between the resistant and susceptible groups to PG14 based on DS values at the seedling stage were confirmed at the adult stage in two locations at least, except for August precipitation, confirmed only in one locality. The relationship between bulk density and resistance at the seedling stage to the HU14 isolate (Table 2) was indirectly confirmed at the adult plant stage at the Jerez location since soils with lower clay content usually had lower bulk density. 


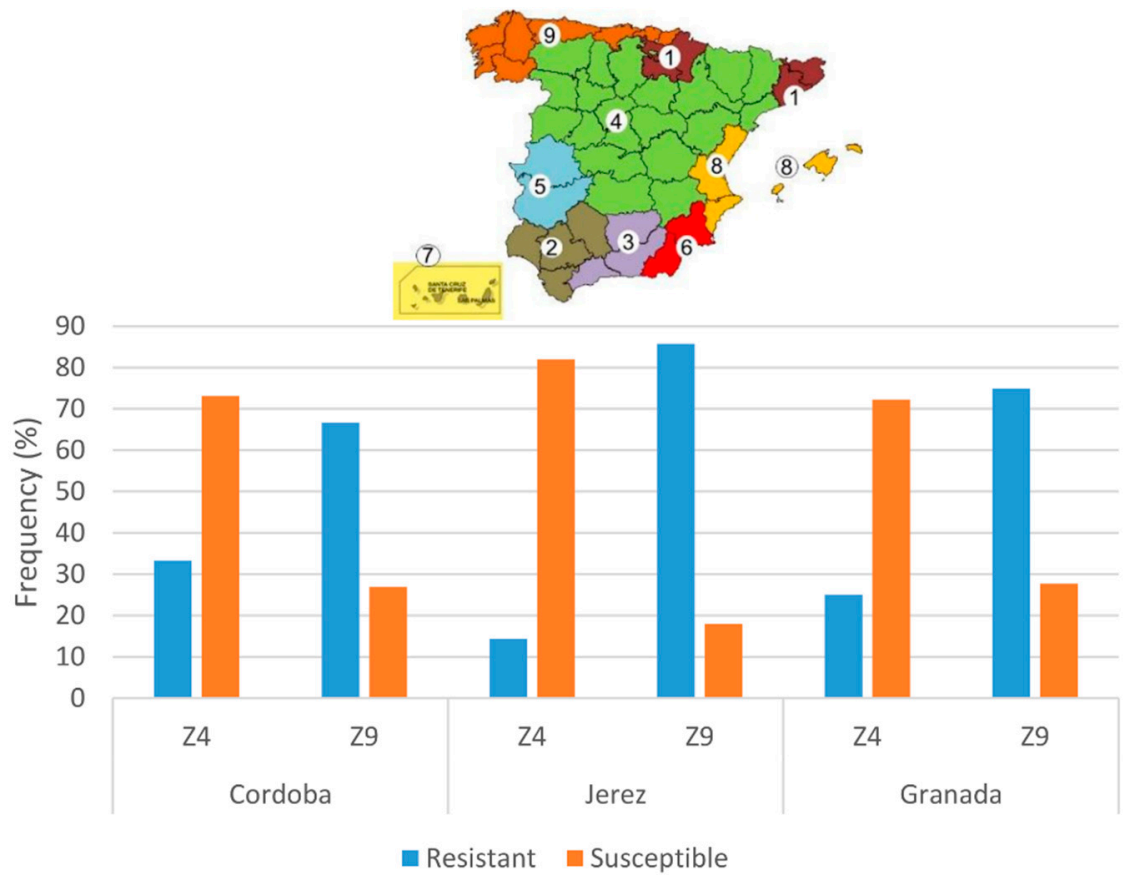

Figure 3. Frequency of leaf rust-resistant landraces from the agroecological zones Z4 and Z9 (defined by [25]) evaluated at the adult plant stage at three locations (Cordoba, Jerez, and Granada).

3.1.6. Selection of Resistant Landraces to Leaf Rust Based on Ecogeographical Variables of the Collecting Site

The classification tree with the ecogeographical variables was only performed for PG14 and the DS groups in the seedling tests. The analyses indicated that the bioclimatic variable Bio_16 (precipitation of the wettest quarter) identified the highest number of resistant landraces. A threshold of 186.48 established was established for Bio_16 selected 23 landraces and $83 \%$ of them were resistant (Table 3). These selected landraces included $73 \%$ of the resistant landraces present in the whole set.

Table 3. Frequency of resistant landraces (\%) to leaf rust (disease severity $\leq 10 \%$ ) in the whole set and in the selected landraces at seedling and adult plant stages at three locations with the threshold values established for precipitation of the wettest quarter (Bio_16).

\begin{tabular}{cccccccccc}
\hline & \multicolumn{2}{c}{ Seedling Stage } & \multicolumn{2}{c}{$\begin{array}{c}\text { Adult Plant Stage } \\
\text { (Cordoba) }\end{array}$} & \multicolumn{2}{c}{$\begin{array}{c}\text { Adult Plant Stage } \\
\text { (Jerez) }\end{array}$} & \multicolumn{2}{c}{$\begin{array}{c}\text { Adult Plant Stage } \\
\text { (Granada) }\end{array}$} \\
\hline & Whole set & Selected & Whole set & Selected & Whole set & Selected & Whole set & Selected \\
\hline Bio_16 $>186.48 \mathrm{~mm}$ & 52 & 83 & 6 & 10 & 13 & 28 & 4 & 6 \\
\hline
\end{tabular}

The threshold established with the seedling tests was used to predict which landraces with geographic coordinates might be resistant or susceptible at the adult plant stage. The application of the threshold selected seven, eight, and four out of the nine, nine, and five resistant landraces at the three locations, Cordoba, Jerez, and Granada, respectively. This identified 78 to $89 \%$ of resistant landraces at the adult stage in the three locations, which slightly increased the frequency of resistant landraces in the selected subset (Table 3).

\subsection{Partial Resistance to Leaf Rust at Seedling Stage in the Greenhouse}

PR to JC13 was assessed in 78 susceptible landraces (IT $\geq 7$ ) by measuring the latency period (Table S2). One landrace (BGE011985) showed a significantly longer LP $(\mathrm{LP}=251.6 \mathrm{~h})$ than the partially resistant check Akabozu $(\mathrm{LP}=246.4 \mathrm{~h})$. The susceptible check Little Club showed an LP of $211.9 \mathrm{~h}$. 
Relations between Seedling Resistance, Agronomic Traits, and Ecogeographical Variables of the Collecting Site

The correlations between agromorphological traits and LP were significant for days to heading and to maturity $(\mathrm{r}=-0.44$ and -0.38 , respectively, $p<0.001)$ and plant height $(\mathrm{r}=0.24, p<0.05)$. The analyses also revealed relevant relationships between LP and the ecogeographical characteristics of the collection site. Landraces from the geographic Zone 9 possessed longer LP than those from Zone 4 ( $\mathrm{LP}=219.73$ vs. 213.88, $p<0.01)$. PR increased significantly with an increase in the precipitation of the landrace site of origin, an increase in the temperature and higher temperature uniformity (Table S6). These relationships can be visualized in the multivariate PCA analysis performed with the LP, the agronomic traits, and the most significant ecogeographical variables of the collecting site of the landraces (Figure 4). The position of the landraces in the biplot indicated that those from Zone 9, areas with higher temperature uniformity and October precipitation, had higher LP values, whereas those from Zone 4 had lower LP values. Earlier and taller genotypes displayed a higher level, but the influence of the climatic variables on LP was greater than those of the agronomic traits.

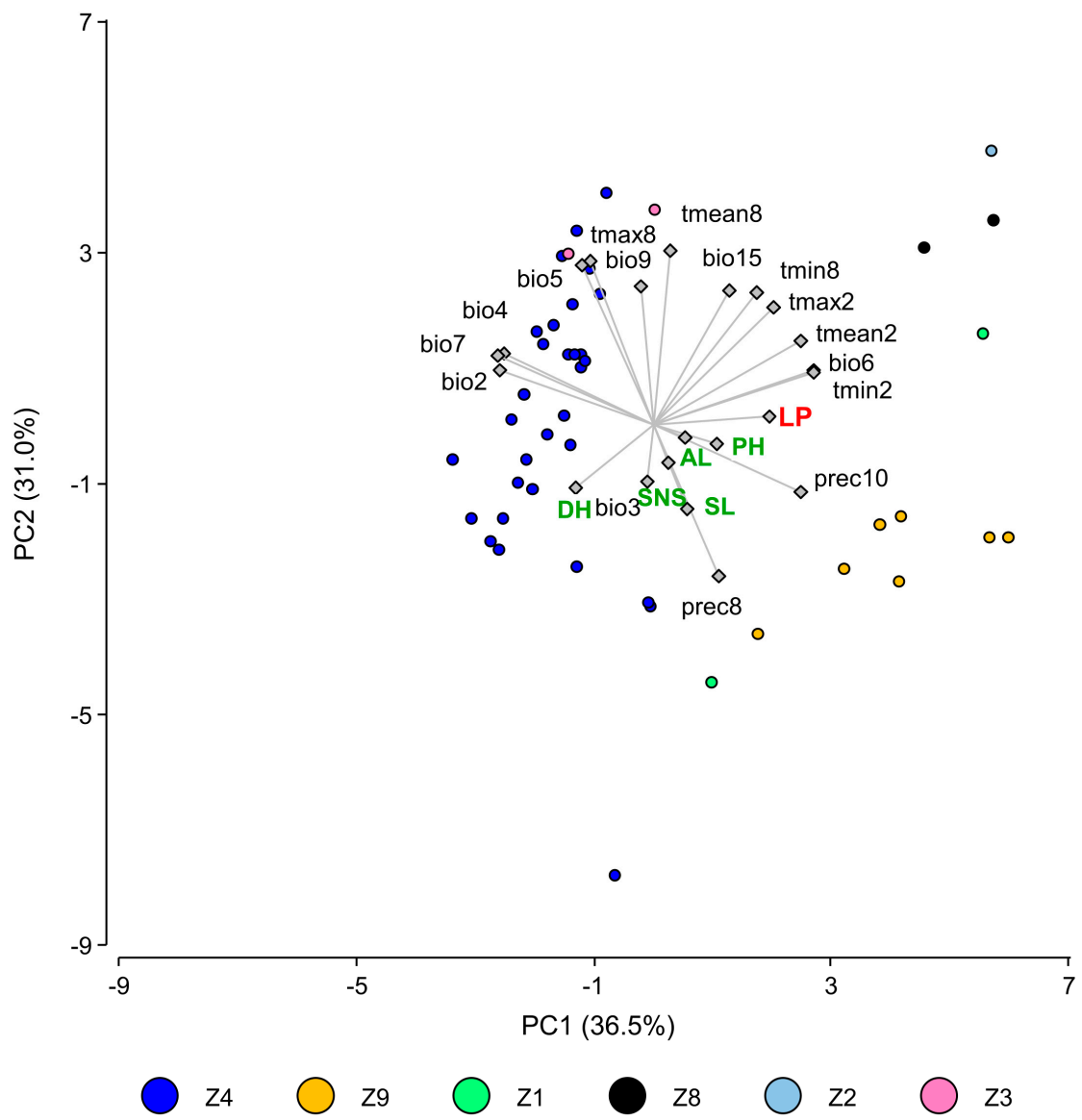

Figure 4. Biplot of the first two axes of the principal component analysis for the latency period at seedling stage (in red), the most significant bioclimatic variables (in black), and agronomic traits (in green). Agroecological zones are indicated in colors. Variables: bio2 = Mean daily temperature range, bio3 = Isothermality, bio4 = Temperature seasonality, bio5 = Maximum temperature of hottest month, bio6 $=$ Minimum temperature of coldest month, bio7 = Annual temperature range, bio9 = Mean temperature of driest quarter, bio15 = Precipitation seasonality, tmean2 = February mean temperature, tmean $8=$ August mean temperature, $\operatorname{tmax} 2=$ February maximum temperature, tmax $8=$ August maximum temperature, $\operatorname{tmin} 2=$ February minimum temperature, $\mathrm{tmin} 8=$ August minimum temperature, prec $2=$ February precipitation, prec $8=$ August precipitation, $\mathrm{AL}=$ awn length, $\mathrm{DH}=$ days to heading, $\mathrm{LP}=$ latency period, $\mathrm{PH}=$ plant height, $\mathrm{SL}=$ spike length, $\mathrm{SNS}=$ spikelets per spike. 


\subsection{Yellow Rust Resistance at Seedling Stage in the Greenhouse}

3.3.1. Correlations between Disease Parameters

The representative subset was also evaluated for yellow rust resistance to the isolate EJ18 at the first leaf stage. The three disease parameters IT, DS, and LN showed significant correlations ( $p<0.01$ ), positive between IT and DS, and negative with LN (Figure 5).

\subsubsection{Identification of Resistant Landraces to Yellow Rust}

Six and sixteen landraces were registered as resistant according to their IT and DS values, respectively (Table S2). The two checks were classified as susceptible according to both disease parameters. Resistant landraces, according to IT, showed significant lower DS ( 3.08 vs. $17.80, p<0.0001)$ than the susceptible landraces. Table S2 shows that landraces in the susceptible IT groups generally had higher DS values.

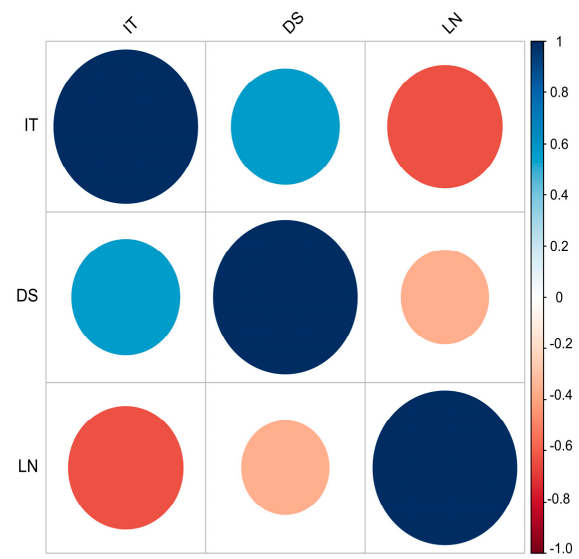

Figure 5. Pearson correlations between the disease parameters infection type (IT), disease severity (DS), and leaf necrosis (LN) assessed for yellow rust at the first leaf at the seedling stage. Coefficients $>|0.18|$ are significant $(p<0.05)$.

\subsubsection{Relations between Seedling Resistance and Agronomic Traits}

For the agronomic traits, IT showed a significant correlation with spike length $(\mathrm{r}=-0.26$, $p<0.05)$, with resistant landraces having longer spikes $(139.2 \mathrm{~mm}$ vs. $114.6 \mathrm{~mm}, p<0.01)$. Landraces classified in the low DS group also had generally longer spikes than those included in the high DS group (124.5 mm vs. $114.47 \mathrm{~mm}$, respectively), although differences were not statistically significant $(p=0.07)$.

3.3.4. Relations between Seedling Resistance and Ecogeographical Variables of the Collection Site

No significant differences were found between Zones 1, 4, and 9 for yellow rust resistance, although Zone 9 included a higher frequency of resistant landraces (Figure 6). This zone also included landraces with longer spikes than those from Zone 4 (137.00 vs. $116.88, p<0.001)$.

The relationship between resistant landraces and the ecogeographical variables was not analyzed for the IT groups because the number of resistant landraces with geographical coordinates was very low. The two DS groups showed significant differences for some bioclimatic variables related to their collection site. Therefore, landraces with lower DS came from areas with more uniform temperature (lower values for temperature seasonality and annual temperature range) and winter precipitation (higher values for precipitation of coldest quarter and December precipitation) (Table S7). A comparison of the ecogeographical conditions of Zone 9 and 4 revealed that landraces from Zone 9 came from areas with significantly lower values for temperature seasonality and annual temperature range, and higher for precipitation of the coldest quarter and December precipitation $(p<0.0001)$ (Table S8). 


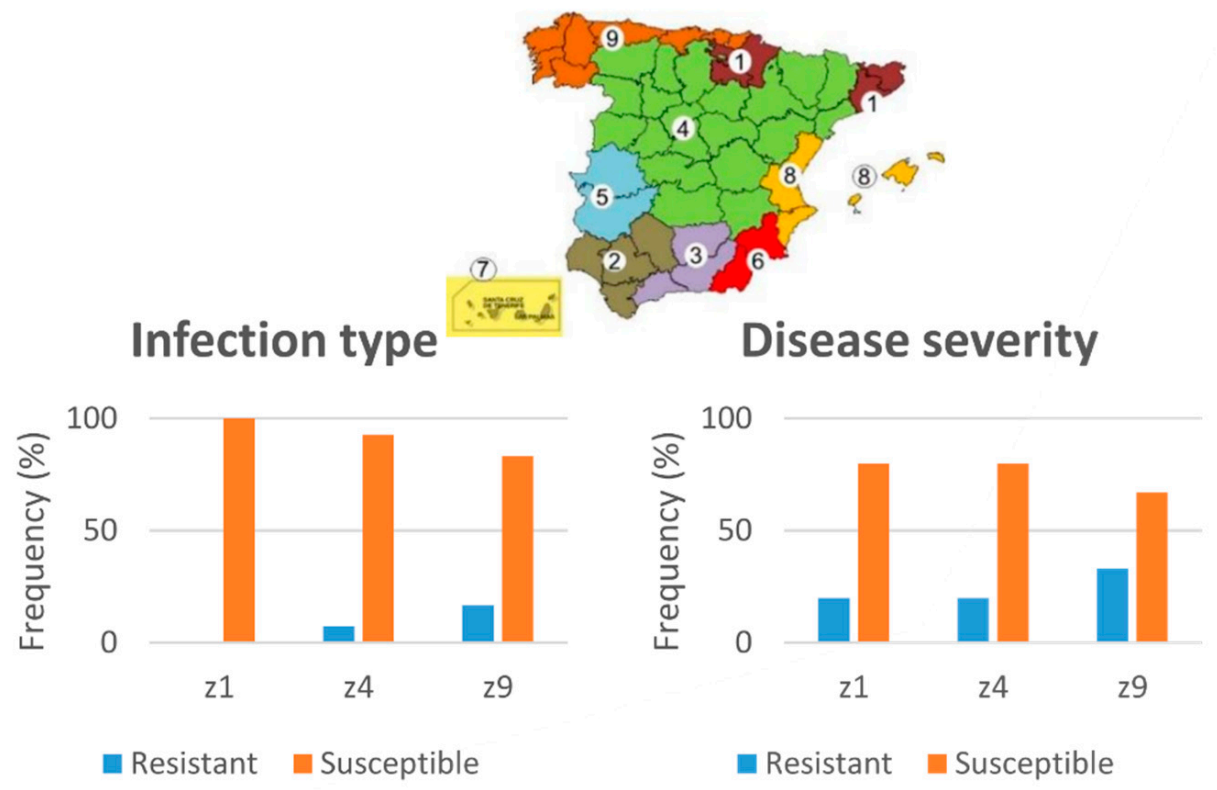

Figure 6. Frequency of resistant landraces to yellow rust at seedling stage in the agroecological zones of Spain Z1, Z4, and Z9 defined by [25].

\subsubsection{Yellow Rust Resistance at Adult Plant Stage in the Field Experiments}

Thirty-four landraces, which included six landraces of the representative set, were tested for yellow rust severity in field plots in the south of Spain (Cordoba) in 1996-1997. In total, $76 \%$ of the landraces were recorded as resistant (Table S4). A significant correlation was found between days to heading and DS ( $\mathrm{r}=-0.42, p=0.01)$, although differences between resistant and susceptible landraces were not significant. All associations between DS at the seedling stage and the ecogeographical variables of the origin site were confirmed in the field evaluations (Table 4 and Table S9). Differences between zones could not be analyzed due to the low number of landraces from most of the zones.

Table 4. Ecogeographical variables ordered according to their significant differences $(p<0.05)$ between resistant (DS $\leq 10)$ and susceptible landraces (DS > 10) to yellow rust at the seedling stage.

\begin{tabular}{ccc}
\hline Isolate & Bioclimatic (Thermal Variables) & Bioclimatic (Hydric Variables) \\
\hline \multirow{2}{*}{ EJ18 } & Temperature seasonality $(-)^{1}$ & Precipitation of coldest quarter $(+)$ \\
& Annual temperature range $(-)$ & December precipitation $(+)$ \\
\hline
\end{tabular}

${ }^{1}$ The (+) or (-) indicates the associations of high or low values of the variable with the resistant landraces.

3.3.6. Selection of Resistant Landraces to Yellow Rust Based on Ecogeographical Variables of the Collecting Site

The classification tree performed with the ecogeographical variables indicated that the climatic variable December precipitation identified the highest number of resistant landraces at the seedling stage according to DS values. Values of December precipitation between 49.30 and $101.14 \mathrm{~mm}$ selected all the resistant landraces, which improved the frequency of resistant landraces (Table 5). The same threshold was used to predict which landraces might be resistant or susceptible at the adult plant stage. In this case, $83 \%$ of the selected landraces were resistant (Table 5). December precipitation higher than $49.30 \mathrm{~mm}$ also selected all the resistant landraces at seedling and the 79\% at adult plant stage, which increased to $90 \%$ the frequency of resistant genotypes. 
Table 5. Frequency of resistant landraces $(\%)$ to yellow rust $(\mathrm{DS} \leq 10)$ in the whole set and in the selected landraces at seedling and adult stages with the threshold values established for December precipitation.

\begin{tabular}{ccccc}
\hline & \multicolumn{2}{c}{ Seedling Stage } & \multicolumn{2}{c}{ Adult Plant Stage } \\
\hline December precipitation $(\mathrm{x})$ & Whole set & Selected & Whole set & Selected \\
\hline $49.30 \mathrm{~mm}<\mathrm{x} \leq 101.14 \mathrm{~mm}$ & 20 & 56 & 75 & 83 \\
$\mathrm{x}>49.30$ & 20 & 36 & 75 & 90 \\
\hline
\end{tabular}

\section{Discussion}

Leaf and yellow rust are two important diseases of bread wheat. The search for wheat landraces resistant to rusts has been constant since the beginning of modern wheat breeding, and a few examples of resistant landraces that were introduced in breeding programs were mentioned in the introduction. When screening large landraces collections for rusts, most landraces are susceptible, suggesting a lower severity of these diseases in the past due to the low intensification of the crop [29]. Still, a few landraces show a resistant response. The percentage of resistant landraces is variable, depending on many factors such as the plant stage, the type of inoculation (natural or artificial), and the race of the pathogen, but normally, the frequency of resistance ranges $5-30 \%$ of the total number of landraces [30-33]. Selection for rust resistance in wheat landraces collections may currently be assisted by the use of DNA markers linked to different $R$-genes, and even genome-wide association analysis can be performed [34-38].

In the present study, a subset of Spanish bread wheat landraces was analyzed for resistance to leaf and yellow rust at the seedling stage. This set represents the genetic variability of more than 500 traditional varieties coming from all the agroecological zones of wheat cultivation in the country. Therefore, the variability found for rust resistance depicts, to a certain extent, the adaptive value of such genetic diversity to the environmental conditions prevailing in each region. Landraces were classified as resistant or susceptible based on two parameters, one qualitative (IT) and another quantitative (DS). This last parameter was also employed in the field screenings at the adult plant stage. Both IT and DS at the seedling and adult plant stage are highly correlated [24]. Our results showed statistical differences in DS for landraces classified as resistant or susceptible by their IT scores. As expected, landraces with higher IT values showed a higher percentage of leaves covered by uredinia. Although susceptibility was the norm, a low (resistant) IT to leaf rust to one or two out of the three isolates employed in this work were found in some landraces and one landrace (BGE013157) had a low IT to the three isolates. Those resistances are based on the hypersensitive reaction, which is frequently found when screening landrace collections [13]. The fact that only one landrace displayed resistance to the three-leaf rust isolates seems to indicate that resistant landraces have different $L r$ genes, which is also consistent with the different virulence spectrum of the isolates that were collected from areas with different agroclimatic conditions. Thus, landraces showing a high IT of uredinia from JC13, and low IT to HU14, may possess Lr10 or Lr20 genes, and there are 25 landraces with this differential response. $L r 20$ is a gene hardly used in modern cultivars due to the common virulence of the leaf rust populations worldwide [39]. The use of Lr10 in modern breeding is limited but often appears in combination with other genes, such as Lr1 and Lr13 $[39,40]$. However, the eight landraces displaying a low IT of uredinia from JC13, and a high IT with HU14 isolate may possess Lr3bg, which is widely dispersed in modern cultivars and probably, as Lr10, has a minor role in gene combinations [39,41]. Another resistance mechanism is partial resistance (PR), which has a polygenic inheritance, and it is phenotypically incomplete but is durable, i.e., the rust spores are not easily able to develop a virulent combination to this kind of resistance. The landrace BGE011985 (Montnegre) displayed a particularly long latency period (the main predictor of PR), and it can be used in breeding programs to increase the PR level of bread wheat cultivars. Landraces BGE013780, BGE018356, and BGE012239 also presented a fair level of PR (although inferior 
to BGE011985). PR often is inherited polygenically, but some of the QTLs involved have a larger effect than others and have been designated as Lr genes. Lr34 (on chromosome 7D), Lr46 (1B), and Lr67 (4D) are examples where PR is concentrated in particular genes, whose resistance is better expressed at the adult plant stage, and sometimes are referred to as adult plant resistance genes [18,42-44]. These genes may be targeted by DNA markers and transferred to other cultivars by backcross [45]. Perhaps one of the landraces selected by their high degree of PR has a QTL of this kind. Currently, there is an increasing interest in exploiting PR to the wheat rusts diseases and combining it with genes for HR. The first type of resistance prolong the durability, the latter for a complete (or near-complete) protection from the rust $[44,46]$. Regarding yellow rust, six landraces were found to be resistant to the isolate used in this study (Chamorro, BGE011932; Rapón, BGE012111; Negro, BGE012752; Jerez, BGE013157; and the two Rojo de Sabando, BGE013801 and BGE018927). Among them, landrace BGE013157 (Jerez) stands out since it was also resistant to the three isolates of leaf rust. This landrace with dual rust resistance is of particular interest not only for research but also for breeding. It is known that some $L r$ genes provide resistance to other rust diseases and even to other non-rust diseases. These cases are extremely rare and involve genes for PR. Thus, Lr34 is pleiotropic with Yr18 (yellow rust resistance), Sr57 (stem rust resistance), and Pm38 (powdery mildew resistance). Lr46 is also Yr29, Sr58, and Pm29, and Lr67 is synonymous with Yr46, Sr55, and Pm46 [44]. The scarcity of those genes does not imply that breeders may broadly use and introduce them in many wheat cultivars. Maybe, landrace BGE013157 have one of those multi-resistance genes or, even better, a new one.

Few relationships concerning agronomic traits to rust resistance were found, but earliness was associated in fewer instances of leaf rust resistance and PR. However, a correlation between resistance to yellow rust and late heading was observed in the collection of Spanish bread wheat landraces. This phenomenon has been reported in other works, and it is not related to plant genetic resistance [47]. A correlation between phenotypic traits and disease susceptibility has been observed in other diseases of wheat. In a set of durum wheat cultivars, the susceptibility to Fusarium head blight (FHB), incited by Fusarium graminearum sensu lato, was inversely correlated with the plant height and flowering biology, the tall and the late heading cultivars being less susceptible [48]. The phenotypic correlations and the genetic relationships between FHB, and agronomic traits have been extensively investigated in bread wheat cultivars, mostly of Chinese origin $[49,50]$.

In the present study, it was shown that earlier genotypes tend to have more yellow rust severity than the late ones because leaves of the earlier landraces possess more spores and have more severity, and the late landraces continue to produce new (and clean) leaves late in the growing season, that partially escapes from yellow rust. Lateness is also an adaptive trait to colder areas, which agrees with yellow rust requires cool temperatures of around $10-15^{\circ} \mathrm{C}$ to develop properly [24]. Regarding the association of low clay soil content-low $\mathrm{pH}$ soil with resistant landraces in the field, it was hard to find any reference to this topic; however, in 1934, Savulescu observed that 'wheat is more severely attacked by rust on neutral to alkaline soils than on acid soils, but acid soils are less favorable for vigorous wheat growth' [51]. A peculiar relationship was found between yellow rust resistance and long spikes. It is known that yellow rust can infect spikes (especially glumes), and in fact, the wheat yellow rust species was named P. glumarum in the past [52,53]. It is likely that longer spikes (with a longer distance between spikelets) may hamper the dispersal of spores between the spikelets of a spike.

The underlying hypothesis for the associations between ecogeographical conditions and resistance to pathogens was that certain types of environments would favour the emergence of rust resistance within in situ populations of landraces [54]. The associations between resistance traits and ecogeographical variables of the collection site can help to identify those environments that are likely to impose selection pressure for the emergence of resistance genes. In the present study, the analyses of 75 ecogeographical variables indicated that there are significant differences between the origin sites of the resistant and 
susceptible landraces according to their DS for the leaf rust (PG14 isolate) and yellow rust at the seedling and adult stage, and for their LP to leaf rust. These differences were mainly related to temperature, uniformity, and precipitation within the growing season (mainly winter), being the hydric variables more significant for hypersensitivity resistance and the thermal ones for PR. Both variables (temperature uniformity and precipitation during winter) are linked to higher severity of leaf rust, and landraces coming from regions with more leaf rust severity are more likely to have a higher level of PR [13].

Temperature is a variable correlated with leaf rust and yellow rust, but only up to a certain extent [24]. For instance, in a study in the UK, it was found a positive correlation between temperature in the growing season and the severity of yellow rust, unless the temperature reaches $23-25^{\circ} \mathrm{C}$, in which case yellow rust is rapidly halted [55]. However, in the present study, temperature uniformity was the variable that showed the greatest significant differences between resistant and susceptible landraces. Temperature uniformity is a feature of littoral and sublittoral areas of Spain, which is the region of origin of many leaf rust-resistant bread wheat landraces and historically the most affected by rust (Asturias, Baleares, Barcelona, Cadiz, Girona, Sevilla, Tarragona) [29]. This variable was also detected in a similar study on resistance to leaf rust in a collection of tetraploid wheat landraces from Spain [31]. In that study, the thermal variables were, contrary to our results, more important than the hydric ones. The areas of durum wheat landraces origin (south and east of Spain) were warmer than the ones of bread wheat (rather distributed throughout the country), and in the south and east of the country, softer and more uniform temperatures favour an adequate leaf rust development [31].

Higher precipitation during winter (which is an important source of humidity, essential for spore germination and infection) also correlated with greater severity of leaf rust $[56,57]$. Landraces from Zone 9 showed a longer LP and are more resistant in the field to leaf rust with respect to other zones such as Zone 4. Zone 9 is located in northern Spain, comprising the province of Asturias, a mountainous region with a temperate Atlantic climate. Wheat has not been historically important in Asturias, but a conspicuous diversity of wheat landraces and species (including emmer and spelt) has been reported in this region for centuries [58,59]. The constant humidity and the temperature uniformity through the growing season have favoured wheat rusts growing in this area, and traditional farmers have selected plants with less rust severity, including PR. Therefore farmers have chosen plants with a higher degree of PR, reflected in the longer LP of landraces from this area [30]. Leaf (and yellow) rust has played a role in the selection of resistant landraces by local farmers and even the selection of more resistant wheat species, such as emmer and spelt, that were abundant in the region [30,31].

Several studies have shown that genetic variation for resistance to diseases can be detected in germplasm originating from locations with an environmental profile similar to the collection sites of a reference set of landraces with known resistance [31,60-62]. The relations between resistance and some ecogeographical variables of the collection site at both seedling and adult stages indicated that landraces from some areas could provide genotypes more resistant to some wheat isolates from Spain $[31,54]$. The goal of the germplasm testing program is to postulate which genotypes have seedling rust resistance genes and to confirm their resistance in the field. In the present study, threshold criteria based on the most significant climatic variables were postulated to classify the landraces as resistant or susceptible to leaf and yellow rust. Both thresholds were for hydric variables related to winter precipitation. The application of these thresholds allowed us to select $73 \%$ and $100 \%$ of the resistant landraces to leaf rust and yellow rust, respectively, at the seedling stage and about $80 \%$ at the adult stage for leaf rust. In addition, the frequency of landraces with seedling resistance increased by approximately $30 \%$ in the selected subsets.

\section{Conclusions}

Although most screened landraces were susceptible, some resistant landraces to leaf and yellow rust have been found in this study. This material could be valuable for de- 
veloping new resistant varieties in breeding programs. The study of the ecogeographical variables from the collection sites showed a relationship between uniform temperature and winter precipitation. Most resistant landraces came from the north of Spain, an area of higher precipitation and more uniform temperature compared with the rest of the country. The particular ecogeographical conditions of this region likely prompted local farmers throughout history to select resistant genotypes. These results may also increase the probability of selecting leaf and yellow rust-resistant landraces in other regions of the Mediterranean Rim and across the world, targeting areas with the associated ecogeographical variables.

Supplementary Materials: The following supporting information can be downloaded at https:/ / www.mdpi.com/article/10.3390/agronomy12010187/s1. Excel file (supplementary tables). Table S2. Disease parameters: infection type (IT), disease severity (DS), and leaf necrosis (LN) of three-leaf rust isolates and one yellow rust isolate, and latency period (LP) for partial resistance to leaf rust. Table S4. Disease severity for leaf rust and yellow rust evaluated in adult plant stage in field plots in each location (Cordoba, Jerez, and Granada). Word file (supplementary tables). Table S1. Ecogeographical variables are considered in the characterization of the bread wheat landraces obtained from various sources compiled by CAPFITOGEN [27] Table S3. Means of the ecogeographical variables (see Table S1) ordered according to their significant differences $(p<0.05)$ between resistant and susceptible landraces, based on their IT and DS values at the seedling stage for the leaf rust isolates Huesca 14 and Peralta García 14. Table S5. Means of the ecogeographical variables (see Table S1) ordered according to their significant differences $(p<0.05)$ between resistant and susceptible landraces, based on their leaf rust severity at the adult stage in field plots at three locations (Cordoba, Jerez, and Granada). Table S6. Pearson correlation $(p<0.05)$ between latency period and ecogeographical variables (see Table S1) evaluated for partial disease resistance to the Jerez Califa 13 isolate at the seedling stage. Table S7. Means of the ecogeographical variables (see Table S1) were ordered according to their significant differences $(p<0.05)$ between the two disease severity groups for yellow rust at the seedling stage. Table S8. Ecogeographical variables were significantly different $(p<0.05)$ between the origin sites of the agroecological zones 4 and 9. Table S9. Means of the ecogeographical variables (see Table S1) were ordered according to their significant differences $(p<0.05)$ between the two disease severity groups for yellow rust at the adult stage in the field evaluation.

Author Contributions: Conceptualization, F.M.-M. and M.R.; methodology, F.M.-M., P.G. and M.R.; software, M.R.; validation, M.R. and F.M.-M.; formal analysis, M.R.; investigation, F.M.-M. and C.N.; resources, P.G. and M.R.; data curation, M.R. and P.G.; writing-original draft preparation, F.M.-M., M.R. and P.G.; writing-review and editing, F.M.-M., M.R. and P.G.; visualization, P.G. and M.R.; supervision, M.R., P.G. and F.M.-M.; project administration, P.G.; funding acquisition, P.G. All authors have read and agreed to the published version of the manuscript.

Funding: This research was funded by grant AGL2016-77149 from MCIN/AEI/10.13039/50110001103 3 and by "ERDF A way of making Europe", grant PIDI2019-109089RB from MCIN/AEI/10.13039/5011 00011033, and project RFP2015-00008-C04-01 from the National Institute for Agricultural and Food Research and Technology.

Institutional Review Board Statement: Not applicable.

Informed Consent Statement: Not applicable.

Acknowledgments: We wish to thank M.I. Blandón, M.N. Fernández-Velázquez, and R. García de Paredes for their technical assistance.

Conflicts of Interest: The authors declare no conflict of interest. The funders had no role in the design of the study, in the collection, analyses, or interpretation of data, in the writing of the manuscript, or in the decision to publish the results.

\section{References}

1. Pascual, L.; Ruiz, M.; López-Fernández, M.; Pérez-Penã, H.; Benavente, E.; Vázquez, J.F.; Sansaloni, C.; Giraldo, P. Genomic analysis of Spanish wheat landraces reveals their variability and potential for breeding. BMC Genom. 2020, 21, 122. [CrossRef]

2. Ruiz, M.; Rodriguez-Quijano, M.; Metakovsky, E.V.; Francisco Vazquez, J.; Carrillo, J.M. Polymorphism, variation and genetic identity of Spanish common wheat germplasm based on gliadin alleles. Field Crops Res. 2002, 79, 185-196. [CrossRef] 
3. Rivero, J. Los Cambios Técnicos del Cultivo de Cereal en España (1800-1930); Ministerio de Agricultura, Alimentación y Medio Ambiente: Madrid, Spain, 2013; ISBN 978-84-491-1285-0.

4. Gadea, M. Trigos Españoles; Instituto Nacional de Investigaciones Agronómicas: Madrid, Spain, 1954.

5. Sánchez-Monge, E. Catálogo Genético de Trigos Españoles; Ministerio de Agricultura: Madrid, Spain, 1957.

6. Ruiz, M.; Metakovsky, E.V.; Rodriguez-Quijano, M.; Vazquez, J.F.; Carrillo, J.M. Assessment of storage protein variation in relation to some morphological characters in a sample of Spanish landraces of common wheat (Triticum aestivum L. ssp. aestivum). Genet. Resour. Crop Evol. 2002, 49, 371-382. [CrossRef]

7. López-Fernández, M.; Pascual, L.; Faci, I.; Fernández, M.; Ruiz, M.; Benavente, E.; Giraldo, P. Exploring the end-use quality potential of a collection of Spanish bread wheat landraces. Plants 2021, 10, 620. [CrossRef]

8. Savary, S.; Willocquet, L.; Pethybridge, S.J.; Esker, P.; McRoberts, N.; Nelson, A. The global burden of pathogens and pests on major food crops. Nat. Ecol. Evol. 2019, 3, 430-439. [CrossRef]

9. Hovmøller, M.S.; Walter, S.; Bayles, R.A.; Hubbard, A.; Flath, K.; Sommerfeldt, N.; Leconte, M.; Czembor, P.; Rodriguez-Algaba, J.; Thach, T.; et al. Replacement of the European wheat yellow rust population by new races from the centre of diversity in the near-Himalayan region. Plant Pathol. 2016, 65, 402-411. [CrossRef]

10. Kolmer, J. Leaf rust of wheat: Pathogen biology, variation and host resistance. Forests 2013, 4, 70-84. [CrossRef]

11. Schwessinger, B. Fundamental wheat stripe rust research in the 21st century. New Phytol. 2016, 213, 1625-1631. [CrossRef]

12. Niks, R.E.; Parlevliet, J.E.; Lindhout, P.; Bai, Y. Breeding Crops with Resistance to Diseases and Pests; Wageningen Academic Publishers: Wageningen, The Netherlands, 2019; ISBN 978-90-8686-328-0.

13. Dinh, H.X.; Singh, D.; Periyannan, S.; Park, R.F.; Pourkheirandish, M. Molecular genetics of leaf rust resistance in wheat and barley. Theor. Appl. Genet. 2020, 133, 2035-2050. [CrossRef] [PubMed]

14. Gill, B.S.; Raupp, W.J.; Browder, L.E.; Cox, T.S. Registration of KS86WGRC02 leaf rust resistant hard red winter wheat germplasm. Crop Sci. 1988, 28, 207. [CrossRef]

15. Klymiuk, V.; Yaniv, E.; Huang, L.; Raats, D.; Fatiukha, A.; Chen, S.; Feng, L.; Frenkel, Z.; Krugman, T.; Lidzbarsky, G.; et al Cloning of the wheat Yr15 resistance gene sheds light on the plant tandem kinase-pseudokinase family. Nat. Commun. 2018, 9, 1-12. [CrossRef] [PubMed]

16. Metzger, R.G.; Silbaugh, B.A. Inheritance of resistance to stripe rust and its association with brown glume color in Triticum aestivum L., 'P.I. 178383'. Crop Sci. 1970, 10, 567-568. [CrossRef]

17. Wang, L.; Ma, J.; Zhou, R.; Wang, X.; Jia, J. Molecular tagging of the yellow rust resistance gene Yr10 in common wheat, P.I.178383 (Triticum aestivum L.). Euphytica 2002, 124, 71-73. [CrossRef]

18. Rubiales, D.; Niks, R.E. Characterization of Lr34, a major gene conferring nonhypersensitive resistance to wheat leaf rust. Plant Dis. 1995, 79, 1208-1212. [CrossRef]

19. Kolmer, J.A.; Singh, R.P.; Garvin, D.F.; Viccars, L.; William, H.M.; Huerta-Espino, J.; Ogbonnaya, F.C.; Raman, H.; Orford, S.; Bariana, H.S.; et al. Analysis of the Lr34/Yr18 rust resistance region in wheat germplasm. Crop Sci. 2008, 48, 1841-1852. [CrossRef]

20. Pascual, L.; Fernández, M.; Aparicio, N.; López-Fernández, M.; Fité, R.; Giraldo, P.; Ruiz, M. Development of a multipurpose core collection of bread wheat based on high-throughput genotyping data. Agronomy 2020, 10, 534. [CrossRef]

21. Zadoks, J.C.; Chang, T.T.; Konzak, C.F. A decimal code for the growth stages of cereals. Weed Res. 1974, 14, 415-421. [CrossRef]

22. McNeal, F.H.; Konzak, C.F.; Smith, E.P.; Tate, W.S.; Russell, T.S. A Uniform System for Recording and Processing Cereal Research Data; US Agricultural Research Services: Wanshington, DC, USA, 1971; pp. 34-121.

23. Peterson, R.F.; Campbell, A.B.; Hannan, A.E. A diagrammatic scale for estimating rust intensity of leaves and stem of cereals. Can J. Res. Sect. 1948, 26, 496-500. [CrossRef]

24. Roelfs, A.P.; Singh, R.P.; Saari, E.E.; International Maize and Wheat Improvement Center. Rust Diseases of Wheat: Concepts and Methods of Disease Management; CIMMYT: Mexico City, Mexico, 1992; ISBN 968612747X.

25. Ruiz, M.; Giraldo, P.; Royo, C.; Villegas, D.; Jose Aranzana, M.; Carrillo, J.M. Diversity and genetic structure of a collection of Spanish durum wheat landraces. Crop Sci. 2012, 52, 2262-2275. [CrossRef]

26. Inventario Nacional de Recursos Fitogenéticos (INIA). Available online: http://webx.inia.es/web_inventario_nacional/ Introduccioneng.asp (accessed on 7 December 2021).

27. Parra-Quijano, M.; Torres, E.; Iriondo, J.M.; López, F. Capfitogen Tools. User Manual Version 2.0. International Treaty on Plant Genetic Resources for Food and Agriculture; FAO Books: Rome, Italy, 2015; ISBN 9789253082551.

28. Kruskal, W.H.; Wallis, W.A. Use of ranks in one-criterion variance analysis. J. Am. Stat. Assoc. 1952, 47, 583-621. [CrossRef]

29. Martínez-Moreno, F.; Solís, I. Wheat rust evolution in Spain: An historical review. Phytopathol. Mediterr. 2019, 58, 3-16. [CrossRef]

30. Martinez, F.; Niks, R.E.; Moral, A.; Urban, J.M.; Rubiales, D. Search for partial resistance to leaf rust in a collection of ancient Spanish wheats. Hereditas 2001, 135, 193-197. [CrossRef]

31. Martínez-Moreno, F.; Giraldo, P.; Cátedra, M.D.M.; Ruiz, M. Evaluation of leaf rust resistance in the Spanish core collection of tetraploid wheat landraces and association with ecogeographical variables. Agricutrue 2021, 11, 277. [CrossRef]

32. Salah-Ud-Din Lodhi, S.; John, P.; Bux, H.; Kazi, A.M.; Gul, A. Resistance potential of Pakistani wheat landraces (Triticum aestivum L.) against stripe rust (Puccinia striformis) and karnal bunt (Tilletia indica). Pak. J. Bot. 2018, 50, 801-806.

33. Beharav, A.; Golan, G.; Levy, A. Evaluation and variation in response to infection with Puccinia striiformis and Puccinia recondita of local wheat landraces. Euphytica 1997, 94, 287-293. [CrossRef] 
34. Bansal, U.K.; Arief, V.N.; DeLacy, I.H.; Bariana, H.S. Exploring wheat landraces for rust resistance using a single marker scan. Euphytica 2013, 194, 219-233. [CrossRef]

35. Fatima, F.; McCallum, B.D.; Pozniak, C.J.; Hiebert, C.W.; McCartney, C.A.; Fedak, G.; You, F.M.; Cloutier, S. Identification of new leaf rust resistance loci in wheat and wild relatives by array-based SNP genotyping and association genetics. Front. Plant Sci. 2020, 11, 1728. [CrossRef] [PubMed]

36. Kumar, D.; Kumar, A.; Chhokar, V.; Gangwar, O.P.; Bhardwaj, S.C.; Sivasamy, M.; Prasad, S.V.S.; Prakasha, T.L.; Khan, H.; Singh, R.; et al. Genome-wide association studies in diverse spring wheat panel for stripe, stem, and leaf rust resistance. Front. Plant Sci. 2020, 11, 748. [CrossRef]

37. Wang, Y.; Yu, C.; Cheng, Y.; Yao, F.; Long, L.; Wu, Y.; Li, J.; Li, H.; Wang, J.; Jiang, Q.; et al. Genome-wide association mapping reveals potential novel loci controlling stripe rust resistance in a Chinese wheat landrace diversity panel from the southern autumn-sown spring wheat zone. BMC Genom. 2021, 22, 34. [CrossRef]

38. Yang, F.; Liu, J.; Guo, Y.; He, Z.; Rasheed, A.; Wu, L.; Cao, S.; Nan, H.; Xia, X. Genome-wide association mapping of adult-plant resistance to stripe rust in common wheat (Triticum aestivum). Plant Dis. 2020, 104, 2174-2180. [CrossRef]

39. McIntosh, R.; Wellings, C.R.; Park, R.F. Wheat Rusts, an Atlas of Resistance Genes; CSIRO Publications: Melbourne, Australia, 1995.

40. Kolmer, J.A. Postulation of leaf rust resistance genes in selected soft red winter wheats. Crop Sci. 2003, 43, 1266-1274. [CrossRef]

41. McCallum, B.D.; Seto-Goh, P. Physiologic specialization of Puccinia triticina, the causal agent of wheat leaf rust, in Canada in 2003. Can. J. Plant Pathol. 2006, 28, 208-213. [CrossRef]

42. Martínez, F.; Niks, R.E.; Singh, R.P.; Rubiales, D. Characterisation of Lr46, a major gene conferring partial resistance to wheat leaf rust. Hereditas 2001, 135, 111-114. [CrossRef]

43. Herrera-Foessel, S.A.; Lagudah, E.S.; Huerta-Espino, J.; Hayden, M.J.; Bariana, H.S.; Singh, D.; Singh, R.P. New slow-rusting leaf rust and stripe rust resistance genes $L r 67$ and Yr46 in wheat are pleiotropic or closely linked. Theor. Appl. Genet. 2011, 122, 239-249. [CrossRef]

44. Ellis, J.G.; Lagudah, E.S.; Spielmeyer, W.; Dodds, P.N. The past, present and future of breeding rust resistant wheat. Front. Plant Sci. 2014, 5, 641. [CrossRef]

45. Ledesma-Ramírez, L.; Solis-Moya, E.; Ramírez-Pimentel, J.G.; Dreisigacker, S.; Huerta-Espino, J.; Aguirre-Mancilla, C.L.; MariscalAmaro, L.A. Relationship between the number of partial resistance genes and the response to leaf rust in wheat genotypes. Chil. J. Agric. Res. 2018, 78, 400-408. [CrossRef]

46. Singh, R.P.; Herrera-Foessel, S.; Huerta-Espino, J.; Singh, S.; Bhavani, S.; Lan, C.; Basnet, B.R. Progress towards genetics and breeding for minor genes based resistance to Ug99 and other rusts in CIMMYT high-yielding spring wheat. J. Integr. Agric. 2014, 13, 255-261. [CrossRef]

47. Danial, D.L. Aspects of Durable Resistance in Wheat to Yellow Rust. Ph.D. Thesis, Wageningen Agricultural University, Wageningen, The Netherlands, 1994.

48. Bentivenga, G.; Spina, A.; Ammar, K.; Allegra, M.; Cacciola, S.O. Screening of durum wheat (Triticum turgidum L. subsp. durum (Desf.) Husn.) Italian cultivars for susceptibility to Fusarium Head Blight incited by Fusarium graminearum. Plants 2021, 10, 68. [CrossRef]

49. He, X.; Singh, P.K.; Schlang, N.; Duveiller, E.; Dreisigacker, S.; Payne, T.; He, Z. Characterization of Chinese wheat germplasm for resistance to Fusarium head blight at CIMMYT, Mexico. Euphytica 2014, 195, 383-395. [CrossRef]

50. Yi, X.; Cheng, J.; Jiang, Z.; Hu, W.; Bie, T.; Gao, D.; Li, D.; Wu, R.; Li, Y.; Chen, S.; et al. Genetic analysis of fusarium head blight resistance in CIMMYT bread wheat line C615 using traditional and conditional QTL mapping. Front. Plant Sci. 2018, 9, 573. [CrossRef] [PubMed]

51. Chester, K. The Nature and Prevention of the Cereal Rust as Exemplified in the Leaf Rust of Wheat; Chronica Botanica Company: Waltham, MA, USA, 1946

52. Cromey, M.G. Infection and control of stripe rust in wheat spikes. N. Z. J. Crop Hortic. Sci. 1989, 17, 159-164. [CrossRef]

53. Zadoks, J.C. Yellow rust on wheat studies in epidemiology and physiologic specialization. Tijdschr. Over Plantenziekten 1961, 67, 69-256. [CrossRef]

54. Broers, L.H.M.; Haan, A.A. Relationship between the origin of European landraces and the level of partial resistance to wheat leaf rust. Plant Breed.-Z. Pflanzenzucht. 1994, 113, 75-78. [CrossRef]

55. Te Beest, D.E.; Paveley, N.D.; Shaw, M.W.; van den Bosch, F. Disease-weather relationships for powdery mildew and yellow rust on winter wheat. Phytopathology 2008, 98, 609-617. [CrossRef]

56. Wiik, L.; Ewaldz, T. Impact of temperature and precipitation on yield and plant diseases of winter wheat in southern Sweden 1983-2007. Crop Prot. 2009, 28, 952-962. [CrossRef]

57. Barkley, A.; Tack, J.; Nalley, L.L.; Bergtold, J.; Bowden, R.; Fritz, A. Weather, disease, and wheat breeding effects on Kansas wheat varietal yields, 1985 to 2011. Agron. J. 2014, 106, 227-235. [CrossRef]

58. Caballero, L.; Martín, L.M.; Alvarez, J.B. Agrobiodiversity of hulled wheats in Asturias (North of Spain). Genet. Resour. Crop Evol. 2007, 54, 267-277. [CrossRef]

59. Alvarez, J.B.; Guzmán, C. Advances in crop science and technology Spanish ancient wheats: A genetic resource for wheat quality breeding. Adv. Crop Sci. Tech. 2013, 1, 101. [CrossRef]

60. El Bouhssini, M.; Street, K.; Joubi, A.; Ibrahim, Z.; Rihawi, F. Sources of wheat resistance to Sunn pest, Eurygaster integriceps Puton, in Syria. Genet. Resour. Crop Evol. 2009, 56, 1065-1069. [CrossRef] 
61. El Bouhssini, M.; Street, K.; Amri, A.; Mackay, M.; Ogbonnaya, F.C.; Omran, A.; Abdalla, O.; Baum, M.; Dabbous, A.; Rihawi, F. Sources of resistance in bread wheat to Russian wheat aphid (Diuraphis noxia) in Syria identified using the Focused Identification of Germplasm Strategy (FIGS). Plant Breed. 2011, 130, 96-97. [CrossRef]

62. Bhullar, N.K.; Zhang, Z.; Wicker, T.; Keller, B. Wheat gene bank accessions as a source of new alleles of the powdery mildew resistance gene Pm3: A large scale allele mining project. BMC Plant Biol. 2010, 10, 88. [CrossRef] [PubMed] 